\title{
From Wilson and Mikity to Hyde
}

Neonatal chronic lung disease (CLD) is actually relevant in a large portion of contemporary neonatal literature. Younger neonatologist, however, should be aware about the "evolution" of this concept, to know how it was reflected in contemporary scientific literature.

This limited review does not dwell on the current findings and advances made on neonatal CLD. Rather, it provides a brief historical scope. In 1960, Drs. Wilson (a pediatrician) and Mikity (a pediatric radiologist) described in Los Angeles (this geographical location is interesting) a small group of newborns which we would consider to be preterm by actual standards, with respiratory distress, although some of them remain asymptomatic, who shared radiological images that nowadays would define as early stages of CLD. They then suggested, perhaps mistakenly, that the probable cause was related to the city's rising levels of smog. ${ }^{1}$

During the following years new ventilation strategies emerged, although rather careless by actual standards; at the same time the mechanisms underlying the then called "hyaline membrane disease" were elucidated.

In 1967 a pediatric radiologist, William H. Northway, and a pathologist, Robert Rossan described a condition they named "bronchopulmonary dysplasia", based on their radiological and histopathological findings. This pioneering work will lay the bases on which would develop the idea of CLD in premature newborns. ${ }^{2}$

In 1975 neonatologists Krauss and Auld ${ }^{3}$ added a bit of confusion to the scene by describing preterm babies whose chest films showed a "haziness" set to become the landmark of what they termed as "chronic pulmonary insufficiency of prematurity" (CPIP). Rapidly, the entity would simply refered to as "Krauss lung".

By the $80^{\prime}$ 's Edwards ${ }^{4}$ attempts to create a new classification bringing in the name of "immature lungs" to describe a similar entity but these babies start off with normal x-rays and surfactant levels.

Lastly, Hyde, in 1989, proposes the term CLD in an effort to avoid different terms relating to similar entities. He first described two different radiological types: type 1 defined as homogeneous or patchy ill-defined opacification without coarse reticulation, and type 2 with the classical appearance of bronchopulmonary dysplasia consisting of streaky densities interspersed with small cystic translucencies. Actual definitions of CLD have emerged from selected consensus and criteria based on oxygen requirements and gestational/postnatal ages plus therapeutic interventions. ${ }^{6-9}$

It is from this stepwise lay-out that CLD has developed its true identity. Although its underlying biogenic and subcellular origins remain elusive, it is known, that, as in the case of retinopathy of prematurity, a true preventive strategy must include prevention of prematurity itself. Although the terms mentioned above are used exceptionally these days, it is likely that each and all of them may be part of a common pathogenic pathway waiting for a definitive answer.

Eduardo Halac, M.D.

Assistant Professor of Pediatrics and Neonatology Universidad Nacional de Córdoba

http:/ /dx.doi.org/10.5546/aap.2016.eng.96

\section{REFERENCES}

1. Wilson MG, Mikity VG. A new form of respiratory disease in premature infants. AMA J Dis Child 1960;99:489-99.

2. Northway WHJr, Rosan RC, Porter DY. Pulmonary disease following respiratory therapy of hyaline-membrane disease. Bronchopulmonary dysplasia. N Engl J Med 1967;276(7):357-68.

3. Krauss AN, Klain DB, Auld PA. Chronic pulmonary insufficiency of prematurity (CPIP). Pediatrics 1975;55(1):55-8.

4. Edwards DK, Jacob J, Gluck L. The immature lung: radiographic appearance, course, and complications. AJR Am J Roentgenol 1980;135(4):659-66.

5. Hyde I, English RE, Williams JD. The changing pattern of chroniclung disease in prematurity. Arch Dis Child 1989;64(4 Spect No):448-51.

6. O'Brodovich HM, Mellins RB. Bronchopulmonary dysplasia. Unresolved neonatal acute lung injury. Am Rev Respir Dis 1985;132(3):694-709.

7. Shennan AT, Dunn MS, Ohlsson A, Lennox K, et al. Abnormal pulmonary outcomes in premature infants: prediction from oxygen requirement in the neonatal period. Pediatrics 1988;82(4):527-32.

8. KinaliM,Greenough A, Dimitriou G, Yüksel B, etal.Chronic respiratory morbidity following premature delivery-prediction by prolonged respiratory support requirement? Eur J Pediatr 1999;158(6):493-6.

9. Jobe AH, Bancalari E. Bronchopulmonary dysplasia. Am J Respir Crit Care Med 2001;163(7):1723-9. 